\title{
VIRTUALITY AND NON-VIRTUALITY IN REMOTE STOCK TRADING
}

\author{
Roger F. A. van Daalen Fuente \\ Mike W. Chiasson \\ Paul R. Devadoss \\ Lancaster University Management School \\ Lancaster, U.K.
}

\begin{abstract}
Advances in information technology allow for remote working, leading to suggestions that remote individuals can operate in virtual instead of face-toface teams. This paper considers the continuation of face-to-face communication in a European group of stock traders, despite the capabilities of information technology to individuate the work. The case illustrates that traders prefer and need to work in face-to-face settings for various reasons. Short-term reasons arise from a need for instant and effortless communication in their manipulation of market prices and for instant knowledge sharing, leading to both higher individual and collective profits. Long-term reasons arise from a need for continuous learning by novices and experts, as stock markets and stock prices settle into behavioral patterns over longer periods of time. The implications for computing and work are discussed.
\end{abstract}

Keywords Community of practice, remote working, electronic trading, knowledge work, information systems, virtuality

\section{INTRODUCTION}

Knowledge exchange appears to be a central issue in the so-called knowledge economy (e.g., Drucker 1993), and the growing importance of specialist knowledge has become of paramount importance (Blackler 1995). The implication is that specialists now own the means of production, resulting in human capital being of greater importance to the firm than any other form of capital (Starbuck 1992).

Please use the following format when citing this chapter:

Van Daalen Fuente, R. F. A., Chiasson, M. W., and Devadoss, P. R., 2008, in IFIP International Federation for Information Processing, Volume 267, Information Technology in the Service Economy: Challenges and Possibilities for the $21^{\text {st }}$ Century, eds. Barrett, M., Davidson, E., Middleton, C., and DeGross, J. (Boston: Springer), pp. 159-172. 
At the same time, information technology has "compressed time and space," allowing for global access to scarce distributed expertise (Ives and Jarvenpaa 1991, p. 33). This allows knowledge workers to work together without regular face-to-face contact through advances in information technology. Given this, it has been repeatedly suggested that effective virtual communities could be formed (Mowshowitz 2002) without (regular) face-to-face communication.

An industry that should be strongly influenced by these developments is the financial services industry. Some have suggested that the prime reason for stock exchanges and the development of this financial system was to lower transaction costs in exchanging capital (North 1991). By moving toward electronic trading, for example with the introduction of the electronic communication networks (ECNs) on the NASDAQ in 1997, stock transaction costs were significantly lowered. The system also allowed for faster trade execution, and provided more complete price information to traders (McAndrews and Stefanidis 2000).

This change allowed for the globalization of trading on financial markets, as access to the markets is now possible from any location. Electronic trading was to replace paper trading, so that traders could do business from anywhere. Barrett and Walsham (1999) argued that this change to remote trading (where traders do not need to meet in person) could radically change the way in which traders establish, continue, and enhance their relationships with each other.

In this paper, we argue that while this form of knowledge work has been influenced by advances in IT, our empirical work illustrates how and why the work is still done in face-to-face groups. Our conclusion is that the face-to-face group continues to act as a socio-technical support system, leading to substantial learning benefits and coordinated action.

The paper is structured as follows. First, a literature review is provided on how the move to electronic trading in financial markets could individuate work. Then, benefits of working in groups in a face-to-face context are put forward. This is followed by the methodology. The case study then explores how and why a case of European traders on the New York stock exchanges continues to work in face-to-face groups. We argue that the fusion of technical and social contact leads to coordinated trading and influence, and to member learning, which is made possible by the immediacy of direct communication. The implications for theory and practice are discussed in the final section.

\section{ELECTRONIC TRADING: DETACHED, INDIVIDUALIZED, AND VIRTUAL?}

The change from paper trading to electronic trading on financial markets is often viewed as an opportunity to decrease the need for human contact in the financial industry, which affects the cost and benefits of market reach. This can lead to changes in the nature and location of contact between individual traders. In the extreme case, trading work can become individualized, detached, and remote.

Barrett (1999) and Barrett and Walsham (1999) have shown how the digital transformations of trading work are often resisted by the traders themselves, for various human and social reasons. A member of the establishment commented that "[traders] feel 
they have to see the whites of their eyes and to see if their hands are trembling [in business transactions]" (Barrett and Walsham 1999, p. 13), signaling a continuing interest in maintaining rich and intense communications when trading by traders. This is contrasted with key players' views that individualization is possible and that traders' contacts can be severely limited. In summary, stock market leaders believed that "electronic trading support enables remote trading to develop with, perhaps, only occasional need for face-to-face interactions to establish or re-establish business relationships" (Barrett and Walsham 1999, p. 20).

Consistent with these possibilities, Knorr Cetina (2002a; 2002b; Knorr Cetina and Bruegger 2000, 2001, 2002) views the change in stock trading work by computer systems as transforming the work from being embodied by a dispersed network of trading partners into a "postsocial" world, wherein humans and objects have changed to relate in new ways. While traders sit next to each other on trading sites, she feels that the computerization of traders' work increasingly disengages them from the local setting. Her view also represents a belief that detachment and individualization is increasingly possible with technological advances in financial work.

Other research (Barrett and Scott 2000, 2004; Scott and Barrett 2005) indicates that the new work environment with IT will lead to a need for different skills. In a physical trading pit, physical cues lead to an embodied feeling for price movements, whereas in the virtual trading pit, intellectual skills will dominate. The informants in that research argue that this will lead to more of a calculative and individualized work environment.

In contrast, Millo et al. (2005) oppose the view that a move from buildings and paper to electronic systems will create a detachment in trading. They argue that the introduction of electronic markets transforms where face-to-face contact takes place, but does not eliminate it. IT does redistribute trading work, but has not lead to isolated individuals working in remote locations. This appears to contrast a common perception that financial markets will be virtualized and individuated by computerized technology.

Thus, while the detached, virtualized, and individualized nature of financial work is possible through the introduction of IT, perhaps motivated by the cost and benefits of globalized work, others argue that it will not and cannot completely do so. To address theoretically why, we turn to two areas of literature on knowledge exchange-dispersed team work and communities-of-practice - that consider the formation and modes of communication in effective groups. This will provide us with a series of theoretical viewpoints to analyze our trading case.

\section{KNOWLEDGE EXCHANGE}

Sapsed and Salter (2004), in reviewing the dispersed team work literature, suggest that knowledge is ordinarily described as locally embedded and difficult to transfer over distances. They also suggest that face-to-face interaction is critical in facilitating the transfer of complex knowledge, and for building trust, commitment, and social capital among participants. They argue that often the absence of face-to-face interaction produces distrust among distant partners, thereby inhibiting the sharing of knowledge.

In general, spatial proximity is considered to enhance organizational communication as it permits intense and ongoing face-to-face interactions. The reason for this is that it is the "richest" form of interaction, despite various (electronic) forms of communication 
such as instant messaging, groupware, videoconferencing, etc. (Daft and Lengel 1986). While it has also been found that experiences through other communication media can also be rich (Carlson and Zmud 1999), most studies find that colocation leads to better knowledge sharing and overall performance than dispersion (Kiesler and Cummings 2002).

As a result, while time and distance can be overcome to virtually connect distant coworkers to each other's knowledge (Finholt et al. 2002) and has been found to allow for collaboration across unprecedented geographic distances (Walsh and Maloney 2002), spatial proximity and face-to-face contact is, at least on occasion, important for the transfer of complex knowledge and the building of social capital (Sapsed and Salter 2004). It thus appears that more is at stake in than just the ability to communicate- - being the development of trust, commitment, and social capital is important to create a desire for exchanging knowledge.

Building on this finding, community-of-practice theory deals specifically with how knowledge is shared and distributed in a work context. Communities-of-practice (COP) are groups of people who share a concern, a set of problems, or a passion about a topic, and who deepen their knowledge and expertise in an area by interacting on an ongoing basis (Wenger 1998; Wenger et al. 2002). Knowledge in COP theory is accumulated at the worksite in a situated sense, and is the result of group processes, and mutual engagement in a common action or idea, which leads to mutual accountability among participants, and a shared repertoire of the "way things are done." Furthermore, Brown and Duguid (1991) built on Orr's $(1987,1990)$ work to explain how knowledge pertains and is transferred in informal relationships, through shared insights and narratives.

Knowledge in a community of practice is accumulated at the work site during situated work, and is the result of group processes (Lave and Wenger 1991). Community-of-practice theory has been said to have originated in a wider tradition of learning, education, and cognitive theories (Fox 2000). Specifically, it has been addressed as a specific version of social learning theory, wherein individual members learn in the workplace (are situated) by participating in shared activity. Knowledge and practice as inherently intertwined was put forward to challenge the then-prevalent view of learning constituted as students "receiving" knowledge in a classroom, and allowing them to exercise that knowledge later on (Lave and Wenger 1991).

Others using this theory have considered enterprises or organizations as constituting a multitude of such communities (Fox 1997a, 1997b). Following this line of reasoning, individual members communally learn by participating in a shared activity in a particular place. In this view, knowledge is transferred within a group by participants, tying learning to ongoing activities in practice.

In short, community-of-practice theory argues that knowledge and practice are intertwined. In this view, learning is acquired through performance. When this is done within a group sharing common interests, knowledge is spread through various means, including socialization. This allows for new entrants to learn quickly about an area of work, through an embodied apprenticeship with others. Both novices and the more experienced members of the community benefit from each others' presence as new insights are shared.

This communal conception of learning in a work context is, in some ways, at odds with the belief that financial work can be performed individually through digital systems. This leads to a key question: Why do communities-of-practice continue to appear when work could be completely individuated? 
Our findings show that face-to-face work still occurs in particular trading communities and for particular reasons, in order to build what the electronic systems cannot deliver. We explore this through the description of a daytrader community in Europe, which trades on various New York stock exchanges.

\section{METHODOLOGY}

Data was gathered during the second half of 2007, as an interpretive (Orlikowski and Baroudi 1991; Walsham 1993, 1995, 2006) in-depth case study (Yin 2003) in and around the work site at TradeCo (a pseudonym) in a major European city. Data collection was focused on the activities and learning of expert and novice daytraders within the community.

The objective was to perceive the understanding of social situations from the viewpoint of participants in a daytrader community at TradeCo. To explore social phenomena within groups and to interpret the meaning attributed to actions by those groups, data collection consisted of semi-structured interviews, participant observation, and secondary data using internal reports of the firm to broaden possible interview topics.

Four different groups of individuals were analyzed in the case. The owner of the company, who is not directly involved in the company's day to day operations, is a gatekeeper to the financial trading capital. The three other groups perform a similar job, with slight variations. Traders trade for TradeCo on the stock markets and receive a portion of their gross profits as compensation. Trainee traders and managers generally do this same work, but trainees do not receive a salary (or any other kind of compensation) until they have proven themselves as good traders. They can do this by "graduating" from trainee to trader by earning $\$ 2,000$ in one month. Managers, in return for a small portion of all the other traders' profits, are responsible for day-to-day operations. Both managers of this daytrader organization, 7 of the 12 traders, 2 trainees, and the owner were interviewed. These 12 semi-structured interviews varied in duration, ranging from 30 minutes up to 2 hours.

In the following, the case data will be contextualized by a short history of the development of the stock market. Following this, the findings are provided, illustrating the activities and methods of learning in this community of traders. Finally, the reasons for their colocated work in both the short- and long-term are discussed.

\section{CASE DATA}

Since the stock market's conception in 1602, people have made a living on the quick trading of stocks, based on price fluctuations. Some traders specialize in very short-term investments, so that each working day represents a cash profit or loss, using only daily holdings in shares. Making a living based on such short-term stock investments is believed to have first been described in the book The Day Trader's Bible (Wyckoff 1919).

With the introduction of electronic communication networks (ECNs), daytraders could work from any location, using computers linked to the respective stock markets. Extending a line of innovations in remote trading which began with the telegraph in the 
mid-1800s, ECNs are an evolutionary broadening of the instant and remote work possibilities of trading.

Many of the reasons for these innovations are related to the dynamic nature of the stock market, where information increasingly loses relevance quickly. Any new information must be acted upon quickly. With the development of the ECNs on the NASDAQ in 1997, fast trade execution was possible from any location in the world, and complete price information was made available to traders (McAndrews and Stefanidis 2000). This change has allowed for the globalization of trading on such markets, as access to financial markets has become possible from any location. The owner of TradeCo commented on trading from a distance:

You know, I've been in this business for almost a decade now. But even though my company has traded 1.5 trillion stocks on the NASDAQ and NYSE, I've only seen a physical stock market once, and that only happened because I took a wrong turn.

In 2004, TradeCo was established, thereby allowing daytraders to work remotely from a location in Europe, operating on the NASDAQ and NYSE. TradeCo is a branch of a global daytrader organization that was founded in 1997.

The daytraders at TradeCo are focused on minimal price differences (in terms of cents) to "shave" stock price differences between ECNs or expected minimal price fluctuations on a single ECN. This type of trading is only possible because of the minimal transaction costs involved in exchanging stocks on an ECN.

\subsection{Work Characterization}

Day trading work has been described as modern knowledge work (Royal and Althauser 2003), as daytraders are essentially investment analysts. The various computer screens used by a trader signal a voluminous amount of information, which is far more detailed and instantaneous than what the occasional investor sees. Traders make shortterm investments in stocks, their contribution being an analysis-primarily based on experience and hunches - of the stock's price, and the buying and selling of investments resulting from quick price changes, sometimes two or three cents. The objective is to benefit from such price movements.

Quick and experienced interpretation of the information is crucial to good decisions. The speed and direction of a price fluctuation is only an estimate, and some estimates are better than others. Novices in this particular profession have a very hard time making any money at the outset. In the words of an early daytrader,

Let anyone who thinks he can make money analyzing the stock market [attempt to trade in a simulated mode]....Put my name down as the opposing side of every trade and when done send me a cheque for what you have lost (Wyckoff 1919, p. 80).

On average, more experienced traders have higher payrolls, supposedly through tacit knowledge. This allows them to make correct predictions of where the stock price is headed more regularly. 
In becoming a good trader, one must figure out both the technical terms being used and how to use the tools at the trader's disposal. Again in the words of an early daytrader,

It seems to us, based on our experience, that Tape Reading is the defined science of determining from the tape the immediate trend of prices. It is a method of forecasting, from what appears on the tape now in the moment, what is likely to appear in the immediate future. Tape Reading is rapid-fire common sense (Wyckoff 1919, p. 7).

Replace tape with electronic price information and tape reading with the art of analyzing price information and this definition is essentially the same today.

\subsection{TradeCo as a Community of Practice}

Day trading is a skill, which can only be learned by actually doing the job. Novices at TradeCo learn by employing daytrader tools in its specific setting, by mistake and correction, through continuous learning. This is far from an individual affair, as the aim and speed of learning by a trainee is often affected by their colocated partners.

For example, sitting near someone with a successful technique can facilitate an immediate transfer of both short and long-term knowledge, so that elements of that technique can be implemented by the trainee. The same holds for more experienced traders, as learning is a perpetual work in progress, and insights are shared quickly between face-to-face workers. As price and stock market behaviors take unexpected turns, learning is a continuous necessity. The situated nature of learning is noticeable for both novices and experts.

Members of the community gain legitimacy as they become experts, often seen and expressed by their income. Legitimization is primarily measured in a trader's salary, which also denotes his rank in the collective. Further to this, the number of screens a trader's desk sports indicates how much money he is able to earn. Trainees and ordinary traders start out with two computer screens. Once they earn $\$ 10,000$, an extra screen will be added ceremoniously and yet another one when a trader has once earned $\$ 20,000$ gross in a single month. When problems arise, the better trader will always be helped first by management. For example, software problems leading to ambiguity in the data stream from the ECNs ordinarily require a phone call to the ECNs to determine how many shares a trader owns or owes, in which case the biggest traders are assisted first.

Because of this, the community of daytraders at TradeCo can be seen as a hierarchical, quick moving, and learning community of practice. This is expressed by the situatedness of learning, and how legitimacy is expressed.

\subsection{Short-Term Communal Learning Benefits}

Within this community of practice, there are a number of short-term learning benefits from colocated work. First, colocation leads to the ability to take short breaks, and this enhances the scope of the market. This is possible because of the community's watchful eye and the quick communication through direct physical presence. Second, knowledge 
is also shared in terms of price behavior estimation from person to community. As they act as a community, opinions on price behavior "stack," so that knowledge becomes a community's opinion.

When little is happening on the stock market, and there are few opportunities for profits, traders resort to social chitchat with their close neighbors, discussing what the stocks might do. Some even go outside for a smoke, or for a glass of mineral water. This is always potentially dangerous, as the market can make a sudden move, so the few traders left "on watch" will shout a loud warning should anything unexpected happen. Traders will then run back to their stations, make a quick evaluation, and resume trading.

Such sharing is not just limited to observation of general trends, but also extends to a communal watching of events: As traders feel cognitively limited to monitor six or seven stock prices at the same time, and nobody can monitor the entire market at the same time, all daytraders specialize in a favorite stock to trade and a few others, which they will vary from day to day. When one daytrader picks up an interesting movement on a stock, he signals this to the group, who will then switch their collective view to this one. All participants can then join in on an unexpected price shift in the market, leading to profits that probably would have been missed by an isolated individual.

Within this environment, success depends on people helping each other, while at the same time benefitting from their collective behavior. During conversations, traders exchange insights to achieve a common understanding of where prices are headed. "Wow, the markets are in bad shape again!" one of the best traders commented. This signals to the other traders that prices will fluctuate more aggressively than usual. Traders help each other out by communally and continuously commenting on their beliefs of where prices are headed.

On one occasion a trader screamed "It's going up, it's going up!," which was followed by another trader pointing out signals that confirmed this conclusion. In the end, the individual is the only one responsible for pushing the buy or sell button, but when experienced daytraders indicate their belief that stock prices are headed in a certain direction, the others will also respond. Thus, while the buy-sell responsibilities are inherently individual, the group at TradeCo collectively helps each other by having their personal analyses "confirmed" by other traders.

Had they worked as individuals instead of as a group, their view on the market would be more constrained, and they would not be able to take breaks. Knowledge is purposefully shared, and traders are socially stimulated to add their opinion to the community's view of what the stock market is doing, with the hope that it will lead to higher individual profits. This also allows them to collectively manipulate stock prices in certain directions. It thus appears that knowledge sharing in this community leads to communal benefits, made possible by instant communication, which may only be possible in a face-to-face situation.

Traders at TradeCo also have tacit agreements not to disrupt and negatively affect another trader's position. Each trader has enough buying power to manipulate stock prices, with each having several million dollars at their disposal. Assume that one trader, for instance, is 10,000 shares "long" (owns that amount of shares) in such a stock. Another trader could manipulate the price by aggressively selling that stock, so that the price would go down.

When asked to comment on why traders share their insights, despite a potential for internal competition, a trader said, 
We have little effect on the world stage of the stock exchange, so we should not bother competing against each other when we can help each other instead. There's plenty of stock market out there for all of us. Also, if we don't help one another, the market is the laughing third party, scooping up what could otherwise have been our communal profits.

Furthermore, individual traders can only "shake" and "move" market prices to some extent on their own. When cooperating in small task force groups, however, they are able to manipulate stock prices further to their advantage. This is especially useful in situations where they feel a price will continue to rise or fall after they have collectively given it a push. When the dollars these traders control are combined, the impact on the market can be enlarged. This is especially useful when they feel a stock price is at a price barrier, and pushing it over or under that barrier would lead to a strong shift in price. Ordinarily, they would then push the price in the direction they would like it to go. On occasions where the stock price gains more momentum beyond the daytraders' combined forces, the continued movement of the stock price leads to a profit when the trade is cashed in after this continued price movement.

It appears, therefore, that traders' knowledge of each others' whereabouts on the market is required and supported within this face-to-face group of traders. The stock market is a continuously moving target, and the ease, intensity, and richness of direct communication allows for such intensive and continuous dialogue. This would be severely hindered by even the best electronic systems.

\subsection{Long-Term Communal Learning Benefits}

In addition to the short-term benefits of sharing knowledge, there are also long-term reasons for working as a group in a colocated setting. There is a continuous need for learning and instant activities, as stock markets and stock price behaviors continuously evolve in unpredictable ways. It can be argued that complex market knowledge is transferred by continuous dialogue across the traders with profitable knowledge.

Being a daytrader is also a continuous learning process, where one must learn the generic adaptation and management of their portfolio with the market, and improve trading skills. As it is a continuous learning process, learning from each others' mistakes and insights is beneficial to all traders.

Knowledge in this case cannot be easily (if at all) captured and distributed through electronic systems. According to one very experienced trader,

I'm genuinely not concerned about making my strategies public, as it really is the trader and his experience that allow him to perceive the proper strategy for the moment and execute it properly. In order to be able to make money and see the opportunities the way I do, and even if someone memorized my reasons, the person first needs to bite the dust on the market and then learn from there with my help.

Thus, as decisions are often split-second, tacit understanding, which can be directly and immediately applied in action, is essential. 
Instead, knowledge sharing consists of hints provided at the right moment in time, when individual and collective activities can be combined in a particular market price situation. In an environment requiring instantaneous communication, the role of information technology is often limited to delivering numerous and instant market signals. Skype and IRC are only used for background reflections and long-term predictions between traders of various daytrader organizations; short-term communication and action is supported by verbal communication only. The high volatility of market knowledge with a very short expiry date makes a face-to-face community-of-practice essential.

One trader reported that he was a trainee for a very long time, until the traders who were sitting next to him quit their jobs because they were no longer able to adapt quickly to the community. The replacements located near him increased his capability.

When they left the company, other traders were relocated nearer to me, and watching them work helped me a lot. By continuously attempting to copy their strategy I managed to earn almost as much money as they did. They showed me why they acted upon which signals and helped me understand what I was doing wrong, as much as what to do and when.

In this instance, observation of currently successful behavior appears to have stimulated the direction and speed of learning over a longer period of time. This tells us that socializing with the currently successful traders is key to individual success.

To summarize, learning is not merely of necessity for the inexperienced new entrants to the organization but is instead a continuous requirement. As the necessary knowledge for trading is complex, a more successful trader "teaching" another trader or a trainee requires quick and intense communication. This appears to be possible only where traders are colocated. In addition, it is argued that socialization between traders provides an impetus for knowledge sharing.

\subsection{Detachment Leads to Diminished Profits}

To further support this claim, there is evidence that those who are under-socialized or excluded from the group do poorly. For example, three traders seated in a more distant area of the office, in a quieter zone, believed they could perform better by just concentrating on the market. Instead, their profits diminished considerably with the passage of time. While they acknowledge that they were not earning as much as they did before, they attributed this to changed market behavior to which they had difficulties adapting, and not to a diminished ability to learn from fellow traders. According to the other traders, however, their increased distance has led to poorer profits than in the past because of their disassociation.

Next, we turn to our discussion of the results and implications for theory and practice.

\section{DISCUSSION AND IMPLICATIONS}

A problem with single case studies is that there is a limitation in generalizability and a risk of observer bias; a multiple site study helps guard against such a bias and adds 
confidence to findings by validating results across sites (Leonard-Barton 1990). Also, a cross-case analysis could specifically seek out a contrasting case to highlight differences between sites (Miles and Huberman 1994). Future research in the form of a multiple site study and cross-case analysis can help address these limitations.

Given this, the case offers a number of insights about the possibilities for IT mediation in this critical industry, where information technology appears able to individuate financial work. It illustrates the continued need for a colocated community of day stock traders. The results of socialization, short- and long-term learning, and decreased performance by isolated individuals provide some evidence for this conclusion.

Confirming our results, Millo et al. (2005) argue that the introduction of electronic markets has not replaced but transformed where the social takes place. This view contrasts with the possibility that the computerization of financial markets could lead to the detached and isolated individuation of financial work.

The current case contributes to the discussion on the role of technology in work transformation by delineating the specific areas where a community of practice is still required-in our case, to be an effective daytrader. In this case, technological intermediation through ECNs allowed quick delivery of information to the remote office of these daytraders, but face-to-face contact among traders was still required. This may suggest that the resistance for virtualized work is not only a nostalgic hope but a workrelated need (Barrett 1999; Barrett and Walsham 1999).

The survey of the literature on community-of-practice theory and dispersed team work suggests that the intensity and richness of face-to-face communication allows for the transfer of complex knowledge. In contrast, electronic communication systems can impede such complex knowledge exchange. It suggests that knowledge transfers are best accommodated by working in a group where trust and collective goals are shared, so that insights are exchanged between novices and experts. This does not imply that there should be little or no IT, but that the final layer of strategic value - in this case, through communal learning and knowledge exchange to beat the markets - is accommodated through colocated teams using the capabilities of IT.

In particular, the literature on community of practice and dispersed team work emphasizes the importance of the social in "sticky" knowledge exchange. This not only arises as a stimulant for knowledge sharing, but also through the performing of individual and shared activities within a group. TradeCo's case provides empirical evidence where and why direct social contact during knowledge exchange are required to produce a community of practice that can "beat the markets."

The COP in this case provides a strangely supportive context and culture for knowledge transfer, with a common incentive or purpose, but where creative work can be individually recognized (Barrett et al. 2004). We build upon and extend this argument by providing an example where contextual circumstances lead to individual success through its dependence on communal coordinated (inter)activity, so that the incentive to share still leads to individual recognition through instant profits. As Barrett et al. (2004) state, "electronic-based contact will often require supplementing with direct face-to-face meetings for complex, delicate trust-based interactions" (p. 9). In our example, electronic-based systems did and probably would not provide for the social and learning benefits that are of crucial importance in successfully working with a fast-moving stock market.

Based on TradeCo's case, we argue that colocation remains of great importance in facilitating learning processes, which impedes the individualization, virtualization, and 
detachment of trading work that appears possible through information technology. The richness and social nature of the community allows knowledge and expertise to spread more completely and rapidly, thereby directing and accelerating the individuals' activities and capabilities within the community. This also provides for short-term benefits in coordination such as internal cooperation and external manipulation, and long-term benefits in the distribution of complex knowledge by facilitating the transfer about renewed market circumstances and general trading practices.

An implication of this research is that strategic knowledge can and does appear in the colocated practices where the new IT capabilities are embedded. This does not eliminate the importance and need for information technology, but illustrates its role in shaping the new and emergent face-to-face communities-of-practice around the introduction of IT. Our paper illustrates how electronic trading alters the sources of electronic and face-to-face communication. In many ways, computerized systems are contributing to a rearrangement of work that began with the earlier application of the telegraph to send stock prices outside of the stock exchange. Thus, more recent developments in information technology have only transformed and broadened the scope of where and how face-to-face work will be done.

\section{References}

Barrett, M. I. 1999. "Challenges of EDI Adoption for Electronic Trading in the London Insurance Market," European Journal of Information Systems (8:1), pp. 1-15.

Barrett, M. I., Cappleman, S., Shoib, G., Walsham, G. 2004. "Learning in Knowledge Communities: Managing Technology and Context," European Management Journal (22:1), pp. 1-11.

Barrett, M. I., and Scott, S. V. 2000. "The Emergence of Electronic Trading in Global Financial Markets: Envisioning the Role of Futures Exchanges in the next Millennium," paper presented at the $8^{\text {th }}$ European Conference on Information Systems, Vienna, Austria, July 3-5.

Barrett, M. I., and Scott, S. V. 2004. "Electronic Trading and the Process of Globalization in Traditional Futures Exchanges: A Temporal Perspective," European Journal of Information Systems (13:1), pp. 65-79.

Barrett, M. I., and Walsham, G. 1999. "Electronic Trading and Work Transformation in the London Insurance Market," Information Systems Research (10:1), pp. 1-22.

Blackler, F. 1995. "Knowledge, Knowledge Work and Organizations: An Overview and Interpretation," Organization Studies (16:6), pp. 1021-1046.

Brown, J. S., and Duguid, P. 1991. "Organizational Learning and Communities-of-Practice: Toward a Unified View of Working, Learning, and Innovation," Organization Science (2:1), pp. 40-57.

Carlson, J. R., and Zmud, R. W. 1999. "Channel Expansion Theory and the Experiential Nature of Media Richness Perceptions," Academy of Management Journal (42:2), pp. 153-170.

Daft, R. L., and Lengel, R. H. 1986. "Organizational Information Requirements, Media Richness and Structural Design," Management Science (32:5), pp. 554-571.

Drucker, P. 1993. Post-Capitalist Society, Oxford, UK: Butterworth-Heinemann.

Finholt, T. A., Sproull, L., and Kiesler, S. 2002. "Outsiders on the Inside: Sharing Know-How Across Space and Time," in Distributed Work, P. Hinds and S. Kiesler (eds.), Cambridge, MA: MIT Press.

Fox, S. 1997a. "From Management Education and Development to the Study of Management Learning," in Management Learning: Integrating Perspectives in Theory and Practice., J. B. Burgoyne and M. Reynolds (eds.), London: Sage Publications. 
Fox, S. 1997b. "Situated Learning Theory Versus Traditional Cognitive Learning Theory: Why Management Education Should Not Ignore Management Learning," Systems Practice (10:6), pp. 727-747.

Fox, S. 2000. "Communities of Practice, Foucault and Actor-Network Theory," Journal of Management Studies (37:6), pp. 853-867.

Ives, B., and Jarvenpaa, S. L. 1991. "Applications of Global Information Technology: Key Issues for Management," MIS Quarterly (15:1), pp. 33-49.

Kiesler, S., and Cummings, J. N. 2002. "What Do We Know about Proximity and Distance in Work Groups," in Distributed Work, P. Hinds and S. Kiesler (eds.), Cambridge, MA: MIT Press.

Knorr Cetina, K. 2002a. "Inhabiting Technology: The Global Lifeform of Financial Markets," Current Sociology (50:3), pp. 389-405.

Knorr Cetina, K. 2002b. "Traders' Engagement with Markets: A Postsocial Relationship," Theory, Culture and Society (19:5/6), pp. 161-185.

Knorr Cetina, K., and Bruegger, U. 2000. "The Market as an Object of Attachment: Exploring Postsocial Relations in Financial Markets," Canadian Journal of Sociology (25:2), pp. 141-168.

Knorr Cetina, K., and Bruegger, U. 2001. "Transparency Regimes and Management by Content in Global Organizations. The Case of Institutional Currency Trading," Journal of Knowledge Management (5:2), pp. 180-194.

Knorr Cetina, K., and Bruegger, U. 2002. "Global Microstructures: The Virtual Societies of Financial Markets," American Journal of Sociology (107:4), pp. 905-950.

Lave, J., and Wenger, E. 1991. Situated Learning: Legitimate Peripheral Participation, Cambridge, UK: Cambridge University Press.

Leonard-Barton, D. 1990. "A Dual Methodology for Case Studies: Synergistic Use of a Longitudinal Single Site with Replicated Multiple Sites," Organization Science (1:3), pp. 248-266.

McAndrews, J., and Stefanidis, C. 2000. "The Emergence of Electronic Communication Networks in the U.S. Equity Markets," Current Issues in Economics and Finance (6:12), pp. 1-6.

Miles, M. B., and Huberman, A. M. 1994. Qualitative Data Analysis: An Expanded Sourcebook, London: Sage Publications.

Millo, Y., Muniesa, F., Panourgias, N. S., and Scott, S. V. 2005. "Organised Detachment: Clearinghouse Mechanisms in Financial Markets," Information and Organization (15:3), pp. 229-246.

Mowshowitz, A. 2002. Virtual Organization: Towards a Theory of Societal Transformation Stimulated by Information Technology, Westport, CT: Greenwood Press.

North, D. C. 1991. "Institutions," The Journal of Economic Perspectives (5:1), pp. 97-112.

Orlikowski, W. J., and Baroudi, J. J. 1991. "Studying Information Technology in Organizations: Research Approaches and Assumptions," Information Systems Research (2:1), pp. 1-28.

Orr, J. 1987. Talking about Machines: Social Aspects of Expertise, Palo Alto, CA: Xerox Palo Alto Research Center.

Orr, J. 1990. "Sharing Knowledge, Celebrating Identity: War Stories and Community Memory in a Service Culture," in Collective Remembering: Memory in Society, D. S. Middleton and D. Edwards (eds.), Beverley Hills, CA: Sage Publications.

Royal, C., and Althauser, R. P. 2003. "The Labor Markets of Knowledge Workers: Investment Bankers' Careers in the Wake of Corporate Restructuring," Work and Occupations (30:2), pp. 214-233.

Sapsed, J., and Salter, A. 2004. "Postcards from the Edge: Local Communities, Global Programs and Boundary Objects," Organization Studies (25:9), pp. 1515-1534.

Scott, S. V., and Barrett, M. I. 2005. "Strategic Risk Positioning as Sensemaking in Crisis: The Adoption of Electronic Trading at the London International Financial Futures and Options Exchange," Journal of Strategic Information Systems (14:1), pp. 45-68. 
Starbuck, W. H. 1992. "Learning by Knowledge-Intensive Firms," Journal of Management Studies (29:6), pp. 713-740.

Walsh, J. P., and Maloney, N. G. 2002. "Computer Network Use, Collaboration Structures and Productivity," in Distributed Work, P. Hinds and S. Kiesler (eds.), Cambridge, MA: MIT Press.

Walsham, G. 1993. Interpreting Information Systems in Organizations, New York: John Wiley and Sons.

Walsham, G. 1995. "Interpreting Case Studies in IS Research: Nature and Method," European Journal of Information Systems (4:2), pp. 74-81.

Walsham, G. 2006. "Doing Interpretive Research," European Journal of Information Systems (15:3), pp. 320-330.

Wenger, E. 1998. Communities of Practice: Learning, Meaning and Identity, Cambridge, UK: Cambridge University Press.

Wenger, E., McDermott, R. A., and Snyder, W. 2002. Cultivating Communities of Practice: A Guide to Managing Knowledge, Boston: Harvard Business School Press.

Wyckoff, R. D. 1919. The Day Trader's Bible. Or. . My Secrets of Day Trading in Stocks, New York: Ticker Publishing.

Yin, R. 2003. Case Study Research ( $3^{\text {rd }}$ ed.), Thousand Oaks, CA: Sage Publications.

\section{About the Authors}

Roger van Daalen Fuente is a Ph.D. student at Lancaster University Management School, Department of Management Science. His research interests include virtuality and social cognition as applied to the study of information systems in the finance industry. He holds a BScBA from RSM Erasmus University in Business Administration and a BSc in Industrial/ Organizational Psychology from the same university. He has worked as an entrepreneur in the IT services sector. Roger can be reached at r.vandaalen@lancaster.ac.uk.

Mike Chiasson is currently an AIM (Advanced Institute of Management) Innovation Fellow and a Senior Lecturer at Lancaster University's Management School, in the Department of Management Science. Before joining Lancaster University, he was an associate professor in the Haskayne School of Business, University of Calgary, and a postdoctoral fellow at the Institute for Health Promotion Research at the University of British Columbia. His research examines how social context affects IS development and implementation, using a range of social theories (actor network theory, structuration theory, critical social theory, ethnomethodology, communicative action, power-knowledge, deconstruction, and institutional theory). In studying these questions, he has examined various development and implementation issues (privacy, user involvement, diffusion, outsourcing, cyber-crime, and system development conflict) within medical, legal, engineering, entrepreneurial, and governmental settings. Most of his work has been qualitative in nature, with a strong emphasis on participant observation. Mike can be reached at m.chiasson@lancaster.ac.uk.

Paul Devadoss is a lecturer at the Department of Management Science, Lancaster University Management School, UK. He completed his Ph.D. in Information Systems at the School of Computing in the National University of Singapore. His research interests include enterprise systems and e-governments. In particular, he is interested in the social impacts of IT use in organizational settings and the managerial implications of technology use. He has previously published in journals such as Decision Support Systems, MIS Quarterly Executive, Communications of the AIS, Information and Management, and IEEE Transactions on IT in Biomedicine. Paul can be reached by e-mail at paul@devadoss.org. 